\title{
Mini-STRs Screening of 12 Relatives of Hausa Origin in Northern Nigeria
}

\author{
1U.U. Akpan, ${ }^{1}$ K. O. Adekoya, ${ }^{* 1}$ E. T. Awe, ${ }^{2}$ N. Garba, ${ }^{1}$ G. D. Oguncoker and ${ }^{1}$ S. G. Ojo \\ ${ }^{1}$ epartment of Cell Biology and Genetics, University of Lagos, P.M.B. 56, Akoka-Lagos, Nigeria \\ 2Department of Medical Laboratory Science, Bayero University, P.M.B. 3011, Kano, Nigeria \\ [Corresponding Author: E-mail: topeawela@gmail.com]
}

\begin{abstract}
The forensic identification of closely related individuals genetically has often been difficult probably due to strong phenotypic concordances. Short tandem repeats (STRs) have been used in kinship tracing, identifying missing person and skeletal remains, paternity testing and mass disasters victim identification. This research was performed to determine the efficiency of the miniSTRsD14S1434 and D9S1122 in differentiating between closely related persons in Nigeria. The sample consisted of twelve individuals who self-identify as relatives. DNA extracted from blood was amplified using primers for the two miniSTR loci and resolved subsequently on 4\% Agarose gel. An initial denaturation for 3 min at $95^{\circ} \mathrm{C}$ with annealing temperature at $57.4^{\circ} \mathrm{C}$ and 30 cycles of PCR produced best results. Different alleles of the markers D9S1122 $(9,10,12,13,14,15,16)$ and D14S1434 $(13,15,17,19,20)$ were identified in the samples studied with a high degree of heterozygosity as seen in the computed estimates of 0.8000 and 0.6364 for the D9S1122 and D14S1434 loci respectively. The gel resolutions show a combined probability of exclusion of 0.94 for the population and 0.97 for siblings. These loci can therefore efficiently differentiate individuals and establish family relationship in the Hausa population and will be important for forensic identification of individuals in the population.
\end{abstract}

Keywords: STRs; identification; Hausa; Nigeria; Alleles

\section{INTRODUCTION}

The identification of members of a family and closely related individuals among humans can often be difficult. The difficulty occurs because related individuals more often than not have strong phenotypic concordances. Different methods were developed and used to resolve forensic cases requiring identification but there are debates on their suitability and resolving power when members of the same family were involved. By the 1980s DNA typing methods using highly polymorphic Restriction Fragment Length Polymorphism (RFLP) and Variable Number Tandem Repeats (VNTR) probes showed far more efficiency than the earlier protein typing method for resolving personal identification cases (Hammond et al. 1994; Jeffreys, et al. 1992).

However these methods had some shortcomings that were remedied using DNA typing based on amplification of Short Tandem Repeats (STR) loci. Application of short tandem repeat analysis for forensics however became the method of choice in the 1990s (Butler, 2005). Although most STR systems have a lower heterozygosity (34\%-90\%) than restriction fragment length polymorphisms (RFLPs) and some amplified fragment length polymorphism (AmpFLPs) (Alford et al. 1994). This heterozygosity is now been improved by increasing the number of system tested and the use of multiplex PCR (Klintschar and Crevenna 1996; Chatumal et al. 2010). When a sufficient number of loci are tested, a genetic profile is generated providing the discriminating power needed for specific human identification (Moretti et al. 2001; Butler 2006).

The development and application of DNA profiling using a core of short tandem repeat (STR) loci is presently the method of choice for identification (Butler, 2005; Awe et al., 2017). These STRs do not perform well in cases where only trace DNA and degraded DNA is the available sample. This led to the development of miniSTR (mini-short tandem repeat) for application especially in kinship tracing, identifying missing persons and skeletal remains, paternity testing and mass disaster victims' identification where the DNA may be degraded or trace amounts recovered. 
Amplification of degraded DNA using STR often results in partial DNA profile with limited statistical value or worse no genetic data. The ability to obtain genetic information from degraded samples is often enhanced through the use of smaller PCR products which were first reported in 1995 with the victims of Waco Branch Davidian Fire and these small sized STR markers are called miniSTR (Eisenberg and Planz, 2007). While standard STR primers target longer sequences that include the STR loci, miniSTR zoom in on the STR locus so that the resulting DNA product is smaller, thereby increasing the chances of successful amplification of the larger loci (Hill et al. 2008).

MiniSTR also requires very small amount of DNA that can be analyzed by other methods except from PCR such as rapid micro channel electrophoretic separations and time-of-flight mass spectrometry (Coble et al., 2005). They are more sensitive, less prone to allelic dropout and more discriminating than the VNTRs and STRs (Roewer, 2013). These miniSTRs were developed to serve as complement to STR loci in the cases where additional loci are needed to generate a DNA profile and these miniSTR loci multiplexes are then called Miniplexes. The STR loci that were focused on had high heterozygosity, small allele size ranges and were capable of making into short amplicons by having clean flanking regions. About 40 miniSTR loci were characterized some of which are DIGATA113, D5S2500, D9S1122, D14S1434, D20S482 and Amelogenin (Butler et al. 2003). These loci are advantageous because they produce short PCR products in the target range of $50-150$ base pairs by moving the primer sequences as close as possible, if not directly next to the identified repeat region (Hill et al. 2008).

The D14S1434 locus has been used very efficiently in China to analyze degraded DNA from mass disaster and forensic casework such as fire disaster, earthquake tsunami and so on. It has high discrimination power and small amplicons in the Chinese Han population showing observed heterozygosity of 0.695 (Jai et al. 2012). It is located on chromosome 14 in the region $14 q 32.13$, observed size is $70-98$ base pair and its repeat motif is CTRT (Hill et al. 2008). It has also provided a very useful DNA profile in the Korean population with observed heterozygosity of 0.770 and said to be as highly informative as CODIS STRs (Chung et al. 2006). Among the US, African American and Caucasians population, this locus has also proven to provide DNA profile because of its power of discrimination (Coble, et al. 2005) and also in the identification of unidentified remains among Mexican American with observed heterozygosity 0.8227 (Eisenberg and Planz, 2007).

In recent times, Nigeria has witnessed a lot of uprising as a result of the activities of terrorism in the northern part of the country, militants operations in the south and other perilous disasters such as building collapse and fatal road accidents. Together with the drive to cub criminality in the country, prompts a need for highly discriminatory tests for identification of individuals at the molecular level. The Hausa people are found chiefly in northwestern Nigeria and the adjacent southern part of Niger republic. They constitute the largest ethnic group in the area, with a population of over 20 million individuals and are one of the largest in Nigeria. The Hausa language belongs to the Chadic group of the Afro-Asiatic (formerly Hamito-Semitic) family and is infused with many Arabic words as a result of Islamic influence. The Hausa live in large compounds often with more than one nuclear family (Hill, 1972). They are highly migrants, travelling to coastal towns in Nigeria and across Africa (Fabusoro, 2007). Descent is patrilineal; and close kin, especially cousins, are preferred marriage partners. Divorce, regulated by Muslim law, is frequent. The males are polygamous, and can marry as many as four wives (Otite, 1991). This relationship structures among the Hausa of course, requires an efficient test to discriminate between individuals.

This study aims to determine the efficiency of the miniSTRs D14S1434 and D9S1122 in differentiating between closely related persons 
of Hausa ethnic group in Nigeria. It is expected the result of this work would pioneer research in the characterization of different miniSTR loci useful in forensic identification of individuals in Nigeria population.

\section{MATERIALS AND METHODS Sample Collection}

This study was part of a larger study on the proficiency of STR in the Nigerian population for which ethical clearance with reference ADM/DCST/HREC/1921 was obtained from the Institutional Review Board (IRB) of the Lagos University Teaching Hospital (LUTH) Nigeria. The informed consent of participants was also obtained.

Five millilitres $(5 \mathrm{ml})$ of blood was collected aseptically by venepuncture from twelve Hausa individuals from Kano who self-identify as relatives (a set of three brothers, two cohorts of two cousins and one set of uncle-nephews). Those samples were transported to the Genetics laboratory of the University of Lagos (in a cooler containing ice) for DNA extraction.

\section{DNA Extraction}

Pipetted $500 \mu \mathrm{L}$ of blood was poured into a 1.5 $\mathrm{mL}$ eppendorf tube and $1000 \mu \mathrm{L}$ of red cell lysis buffer was added. The microfuge tube was shaken gently (up to homogenizing) and then spun for 2 minutes at $7000 \mathrm{rpm}$. Supernatant was discarded and the first two steps were repeated thrice to remove haemoglobin. The tubes were air dried of smearing supernatants by placing them downward on tissue paper for few seconds and caution was taken to avoid cross-contamination between different samples. Exactly $400 \mu \mathrm{L}$ of nucleic lysis buffer was added to eppendorf tubes and if pellets formed, this was pipetted up to dissolve it. Then $100 \mu \mathrm{L}$ of saturated $\mathrm{NaCl}(5 \mathrm{M})$ and $600 \mu \mathrm{L}$ of chloroform were added to the tubes. These were then mixed on a rotating blood mixer at room temperature and then spun for 2 minutes at $7000 \mathrm{rpm}$. Afterwards, $400 \mu \mathrm{L}$ of supernatant was transferred to a new $1.5 \mathrm{~mL}$ eppendorf tube into which $800 \mu \mathrm{L}$ of ice cold absolute ethanol was added to the new eppendorf tubes and then vortexed. DNA appeared as a mucus- like strand in the solution phase. The microfuge tubes were spun for one minute at $12000 \mathrm{rpm}$ to precipitate, supernatant discarded carefully and the tubes were completely dried in room temperature. Finally, $50 \mu \mathrm{L}$ of TE buffer was added then vortexed. The tubes containing DNA were stored at $-20^{\circ} \mathrm{C}$ until PCR was performed.

\section{PCR Amplification}

This was carried out using a total reaction mix of $20 \mu \mathrm{L}$ which consisted of $4 \mu \mathrm{L}$ of master mix (containing Taq DNA polymerase, dNTPs, $\mathrm{MgCl}_{2}$ and reaction buffers), $2 \mu \mathrm{l}$ of DNA, $1 \mu \mathrm{L}$ of each primer with the primer sequence according to Hill, et al. (2008):

(D14S1434:

Forward:

TGTAATAACTCTACGACTGTCTGTCTG

Reverse: GAATAGGAGGTGGATGGATGG and

D9S1122:

Forward

GGGTATTTCAAGATAACTGTAGATAGG

Reverse

GCTTCTGGAAAAGCTTCTAGTTTACC) and $12 \mu \mathrm{L}$ of distilled water. The PCR protocol is as follows; Initial denaturation for $3 \mathrm{~min}$ at $95^{\circ} \mathrm{C}$, denaturation for $30 \mathrm{~s}$ at $95^{\circ} \mathrm{C}$, annealing for $30 \mathrm{~s}$ at $57.4^{\circ} \mathrm{C}$, extension for $1 \mathrm{~min}$ at $72^{\circ} \mathrm{C}$ (30cycles), final extension for $10 \mathrm{~min}$ at $72^{\circ} \mathrm{C}$, and hold at $10^{\circ} \mathrm{C}$.

\section{Agarose Gel Electrophoresis}

Prior to PCR amplification, a yield gel was performed to assess the size of the extracted DNA in each sample. The samples was run on $1 \%$ agarose gel using 0.5xTBE (Tris/Borate/EDTA) buffer and ethidium bromide as visualizing stain. The PCR products were resolved on a $4 \%$ agarose gel at 70 volts for 45 minutes. Twenty base pair (20bp) DNA ladder was loaded as DNA size marker to monitor the bands sizes. Into each well, $5 \mu$ of the DNA sample with $2 \mu \mathrm{l}$ of loading dye were dispensed and the power pack switched on. The gels were then viewed with a UV transilluminator and subsequently documented.

\section{Statistical Analysis}

The frequency of each allele for each locus was calculated from the numbers of each genotype obtained in the sample set (i.e. the gene count 
method). The software PopGene32 was used to calculate the observed and expected homozygosity, as well as the observed and expected heterozygosity. In addition, unbiased estimates of expected heterozygosity as described by Nei (1987) and the F-statistics were computed using the same program. Possible divergence from Hardy-Weinberg expectations (HWE) was tested by calculating the unbiased estimate of the expected homozygote/ heterozygote frequencies and the exact test using the program GenAlExv.6.502. The number of effective alleles, Shannon's information index, Probability of identity, power of exclusion (PE) was calculated using GenAIExv.6.502. The software Power Marker was used to compute the PIC (Polymorphism information content) for the loci.

\section{RESULTS}

The majority of the 12 samples investigated showed the same allele sizes for loci D14S1434 of $98 \mathrm{bp}$, in wells $2,3,6,7,8,9,10,11,12$ (Plate 1, Table 1).

A total of seven and five alleles were observed at the loci D9S1122 and D14S1434 (Table 1). The distributions for the observed allele frequencies for the two loci are shown in Table 2. Both loci showed a high degree of heterozygosity and were highly polymorphic for the population under study (Table 2). The alleles at both loci are in Hardy-Weinberg equilibrium

(Table

3).

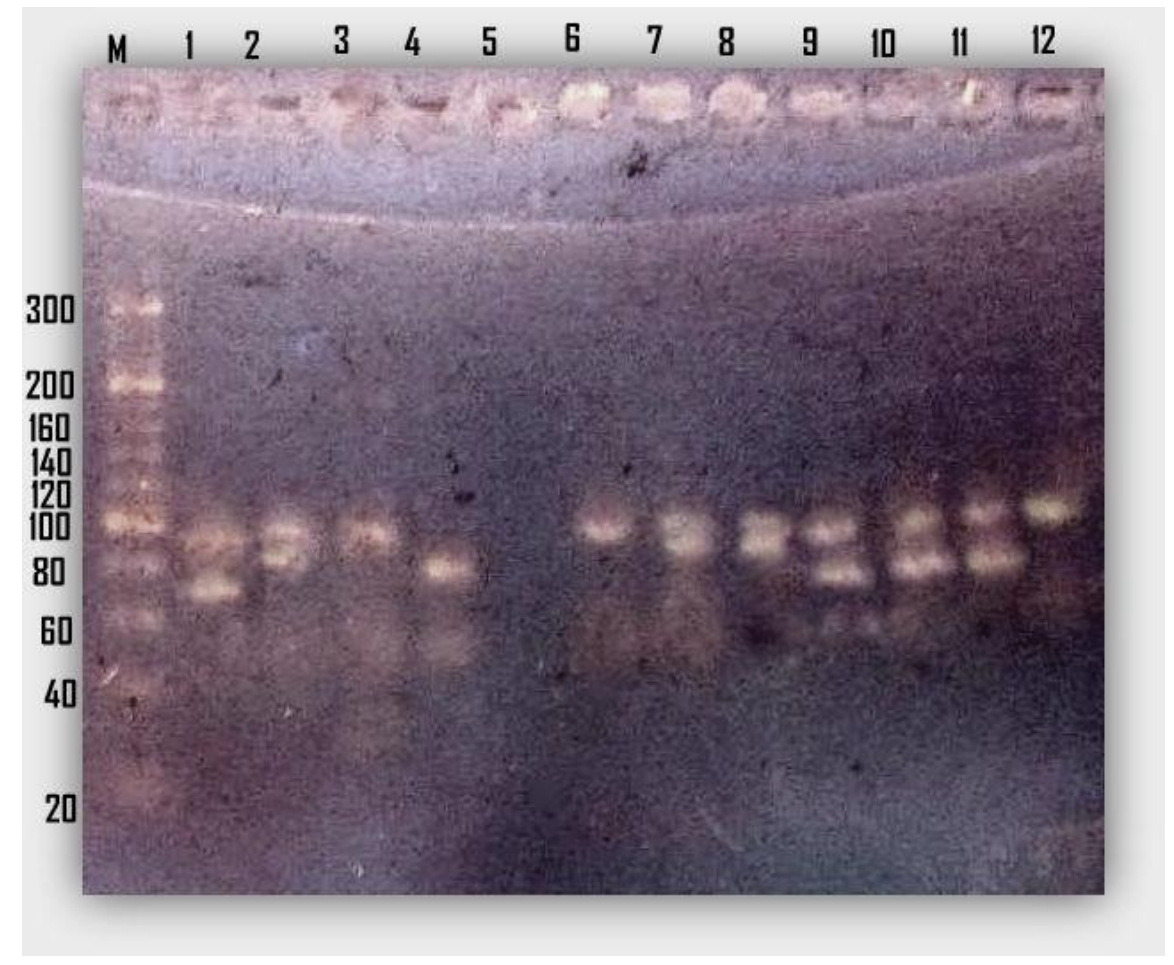

Plate 1: The gel lane M, was loaded with the 20bp ladder. The gel lanes 1-12 contains amplified DNA of D14S1434 for all the 12 individuals sampled (Summary in Table 1) 


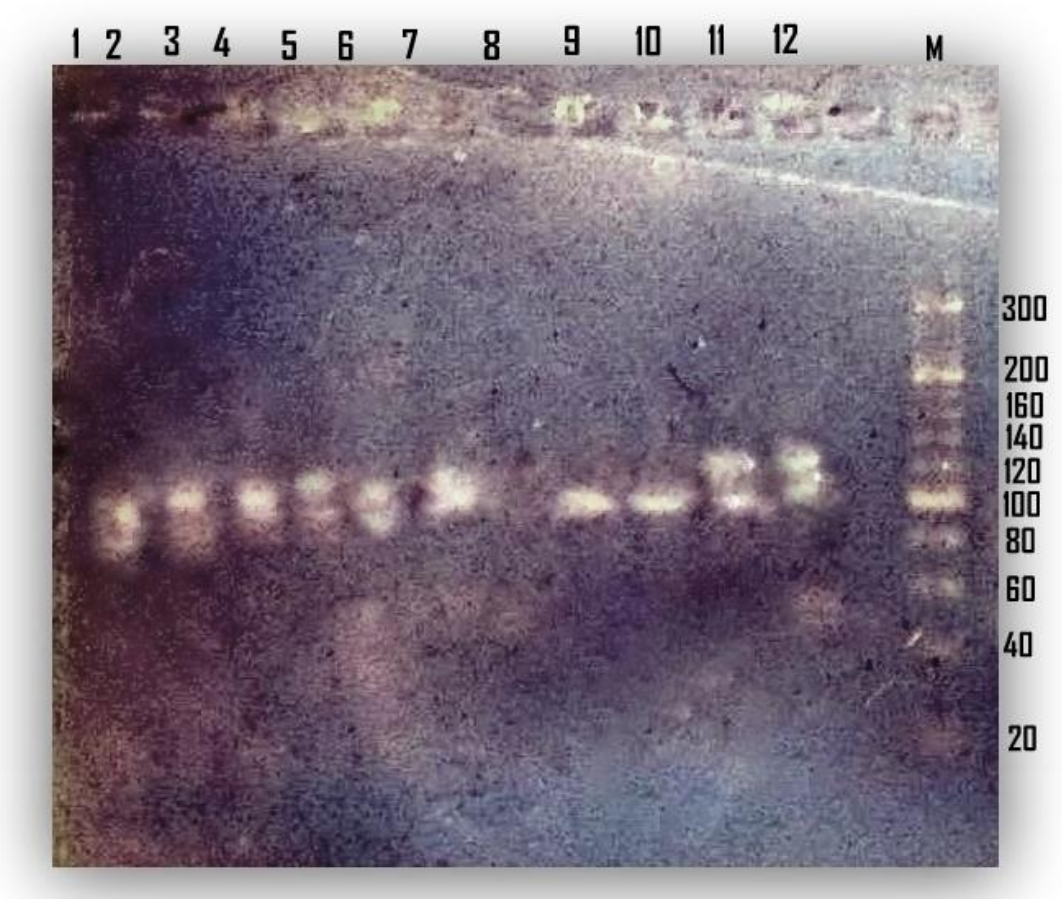

Plate 2: The gel lane M, was loaded with the 20bp ladder. The gel lanes 1-12 contains amplified DNA of D9S1122 for all the 12 individuals sampled. The sample individual 1 (well 1) did not produce amplicon. Individual 2 has the amplicon sizes aout 93 and 109, while individual in well 12 has amplicon sizes 109,121 (Fig 2, summary in Table 1).

Table 1: Allele assignment (Scoring) for each individual from observed band sizes

\begin{tabular}{|c|c|c|c|c|c|}
\hline & & D9S1122 & D9S112 & D14S1434 & D14S1434 \\
\hline $\begin{array}{l}\text { Individual } \\
\text { /well } \\
\text { number? }\end{array}$ & Relationship & $\begin{array}{l}\text { Product Size } \\
\text { (bp) }\end{array}$ & Allele & $\begin{array}{l}\text { Product } \\
\text { size }\end{array}$ & Allele \\
\hline 1 & & - & - & 70,94 & 13,19 \\
\hline 2 & Brothers & 93,109 & 9,13 & 86,98 & 17,20 \\
\hline 3 & & 93,113 & 9,14 & 98,98 & 20,20 \\
\hline 4 & & 97,113 & 10,14 & 78,78 & 15,15 \\
\hline 5 & Cousins & 97,117 & 10,15 & - & - \\
\hline 6 & & 105,113 & 12,14 & 98,98 & 20,20 \\
\hline 7 & Cousins & 109,117 & 13,15 & 94,98 & 19,20 \\
\hline 8 & & - & - & 94,98 & 19,20 \\
\hline 9 & Brothers & 105,105 & 12,12 & 70,98 & 13,20 \\
\hline 10 & & 105,105 & 12,12 & 70,98 & 13,20 \\
\hline 11 & & 105,121 & 12,16 & 70,98 & 13,20 \\
\hline 12 & $\begin{array}{l}\text { Uncle to } \\
8,9,10,11\end{array}$ & 109,121 & 13,16 & 98,98 & 20,20 \\
\hline
\end{tabular}


The sample size, number of alleles, number of effective alleles, Shannon information index and heterozygosity values are presented in Table 4. The probabilities of Identity and Probabilities of Exclusion for both loci are presented in Table 5. A measure of the inbreeding is presented as a table of Fixation indices on Table 6 . The markers show a combined probability of exclusion of 0.94 for the population and 0.97 for siblings (Table 8). There were 28 and 15 different genotypes observed for the D9S1122 and D14S1434 loci respectively (Table 9).

Both loci showed a high degree of heterozygosity and were highly polymorphic for the population under study (Table 2). There were 28 and 15 different genotypes observed for the D9S1122 and D14S1434 loci respectively (Table 9 ). A total of seven and five alleles were observed at the loci D9S1122 and D14S1434. The distributions for the observed allele frequencies for the two loci are shown in Table 2. The alleles at both loci are in HardyWeinberg equilibrium (Table 4).
The sample size, number of alleles, number of effective alleles, Shannon information index and heterozygosity values are presented in Table 4. The probabilities of Identity and Probabilities of Exclusion for both loci are presented in Table 5. The markers show a combined probability of exclusion of 0.94 for the population and 0.97 for siblings. A measure of the inbreeding is presented as a table of fixation indices on Table 6.

Table 2: Allele type and Frequencies for the Markers D9S1122and D14S1434

\begin{tabular}{llll}
\hline $\begin{array}{lll}\text { D9S1122 } \\
\text { Allele }\end{array}$ & Frequency & $\begin{array}{l}\text { D14S1434 } \\
\text { frequency }\end{array}$ & \\
\hline 9 & 0.1 & 13 & 0.1818 \\
10 & 0.05 & 15 & 0.0909 \\
12 & 0.35 & 17 & 0.0455 \\
13 & 0.15 & 19 & 0.1364 \\
14 & 0.15 & 20 & 0.5455 \\
15 & 0.1 & & \\
16 & 0.1 & & \\
\hline
\end{tabular}

Table 3 Hardy-Weinberg Equilibrium Test

\begin{tabular}{llllll}
\hline \multirow{2}{*}{ Locus } & $\begin{array}{l}\text { Chi } \\
\text { Square } \\
\text { value }\end{array}$ & $\begin{array}{l}\text { Chi } \\
\text { Square } \\
\text { d.f. }\end{array}$ & $\begin{array}{l}\text { Chi } \\
\text { Square } \\
\text { p-value }\end{array}$ & $\begin{array}{l}\text { Exact p- } \\
\text { value }\end{array}$ & Signif \\
\hline D9S1122 & 18.88889 & 21 & 0.592268 & 0.462 & Ns \\
D14S1434 & 12.98611 & 10 & 0.224449 & 0.305 & Ns \\
\hline
\end{tabular}

Table 4: Allele Distribution and Level of Heterozygosity

\begin{tabular}{lllllllllll}
\hline Locus & $\begin{array}{c}\text { Sample } \\
\text { Size }\end{array}$ & $\mathrm{Na}$ & $\mathrm{Ne}$ & $\mathrm{I}$ & $\begin{array}{l}\text { Obs_ } \\
\text { Hom }\end{array}$ & Ho & $\begin{array}{l}\text { Exp_ } \\
\text { Hom }\end{array}$ & He & uHe & $\begin{array}{l}\text { Ave } \\
\text { Het }\end{array}$ \\
\hline D9S1122 & 20 & 7.0000 & 5.0000 & 1.777 & 0.2000 & 0.8000 & 0.1579 & 0.8421 & 0.8000 & 0.8000 \\
& & & & 1 & & & & & & \\
D14S1434 & 22 & 5.0000 & 2.7816 & 1.270 & 0.3636 & 0.6364 & 0.3290 & 0.6710 & 0.6405 & 0.6405 \\
& & & & 8 & & & & & & \\
Mean & 21 & 6.0000 & 3.8908 & 1.523 & 0.2818 & 0.7182 & 0.2434 & 0.7566 & 0.7202 & 0.7202 \\
St. Dev & & 1.4142 & 1.5686 & 0.358 & 0.1157 & 0.1157 & 0.1210 & 0.1210 & 0.1128 & 0.1128 \\
& & & & 1 & & & & & & \\
\hline
\end{tabular}

$\mathrm{Na}=$ No. of Different Alleles; Ne = No. of Effective Alleles; I = Shannon's Information Index;Ho = Observed Heterozygosity;He = Expected Heterozygosity; $\mathbf{u H e}=$ Unbiased Expected Heterozygosity; $\mathbf{F}=$ Fixation Index 


\section{DISCUSSION}

The computed population data for the two loci from selected individuals from the Hausa ethnic group in Northwest Nigeria in this study has established that the mini-STRs can be used for both parentage testing and personal identification among the Hausas to a high degree of confidence. The relative high number of genotypes obtained from the 12 individuals demonstrates a high degree of heterozygozity as seen in the computed estimates of 0.8000 and 0.6364 for the D9S1122 and D14S1434 loci respectively (Table 4). For the D9S1122 locus, this value is close to, but higher than the values obtained in the US African American (0.753), US Caucasian (0.724) and US Hispanic populations (0.686) (Hill et al. 2008). The values obtained for the loci in this study may yet be the highest observed for this locus compared to previous studies.

Table 5: Gene Variation Statistics for All Loci D9s1122 and D14s1434

\begin{tabular}{llllll}
\hline \multirow{2}{*}{ Locus } & $\begin{array}{l}\text { Major } \\
\text { Allele } \\
\text { Frequency }\end{array}$ & $\begin{array}{l}\text { No. of } \\
\text { Genotypes }\end{array}$ & $\begin{array}{l}\text { Gene } \\
\text { Diversity }\end{array}$ & PIC & F \\
& & & & & \\
\hline D9S1122 & 0.3 & 9 & 0.83 & 0.8 & 0 \\
D14S1434 & 0.54 & 6 & 0.64 & 0.6 & 0.0065 \\
Mean & 0.42 & 7.5 & 0.73 & 0.7 & 0.0032 \\
\hline
\end{tabular}

Table 6: F-Statistic and Gene Flow for All Loci

\begin{tabular}{|c|c|c|c|c|c|}
\hline Locus & $\begin{array}{l}\text { Sample } \\
\text { Size }\end{array}$ & Fis & Fit & Fst & $\mathrm{Nm}^{*}$ \\
\hline D9S1122 & 20 & 0 & 0 & 0 & $* * * *$ \\
\hline D14S1434 & 22 & 0.0065 & 0.0065 & 0 & $* * * *$ \\
\hline Mean & 21 & 0.0029 & 0.0029 & 0 & 1000 \\
\hline
\end{tabular}

Table 7: Fixation index (Fis) for each allele

\begin{tabular}{rrrr}
\multicolumn{1}{l}{$\begin{array}{l}\text { D9S1122 } \\
\text { Allele }\end{array}$} & \multicolumn{2}{c}{ D14S1434 } & Frequency \\
& & Allele & \\
\hline 9 & -0.1111 & 13 & -0.2222 \\
10 & -0.0526 & 15 & 1 \\
12 & 0.3407 & 17 & -0.0476 \\
13 & -0.1765 & 19 & -0.1579 \\
14 & -0.1765 & 20 & -0.1 \\
15 & -0.1111 & & \\
16 & -0.1111 & & \\
Total & 0 & & 0.0065 \\
\hline
\end{tabular}


Nigerian Journal of Basic and Applied Science (June, 2017), 25(1): 48-57

Table 8: Probabilities of Identity and Exclusion

\begin{tabular}{|c|c|c|c|c|c|c|c|}
\hline \multicolumn{2}{|c|}{$\begin{array}{l}\text { Probability of Identity } \\
\text { (PI and PI Sibs) }\end{array}$} & \multirow{2}{*}{\multicolumn{2}{|c|}{$\begin{array}{l}\text { For increasing } \\
\text { Locus }\end{array}$}} & \multicolumn{4}{|c|}{$\begin{array}{l}\text { Probability of Exclusion } \\
\text { (P3 and P3Max) }\end{array}$} \\
\hline \multirow[b]{2}{*}{ By Locus } & & & & \multirow[b]{2}{*}{ By Locus } & & \multirow{2}{*}{\multicolumn{2}{|c|}{$\begin{array}{l}\text { For Increasing } \\
\text { Locus } \\
\text { Combinations }\end{array}$}} \\
\hline & & Combi & ations & & & & \\
\hline D9S1122 & D14S1434 & 1 & $1+2$ & D9S1122 & D14S1434 & 1 & $1+2$ \\
\hline 0.052 & 0.17 & 0.052 & 0.0087 & 0.84 & 0.61 & 0.84 & 0.94 \\
\hline 0.35 & 0.47 & 0.35 & 0.17 & 0.87 & 0.77 & 0.87 & 0.97 \\
\hline
\end{tabular}

Table 9a: Summary of Genotype frequencies (D9S1122)

\begin{tabular}{|c|c|c|}
\hline Genotype & $\begin{array}{c}\text { No. } \\
\text { Observed }\end{array}$ & $\begin{array}{c}\text { No. } \\
\text { Expected }\end{array}$ \\
\hline $9-9$ & 0 & 0.1 \\
\hline $9-10$ & 0 & 0.1 \\
\hline $10-10$ & 0 & 0.025 \\
\hline $9-12$ & 0 & 0.7 \\
\hline $10-12$ & 0 & 0.35 \\
\hline $12-12$ & 2 & 1.225 \\
\hline $9-13$ & 1 & 0.3 \\
\hline $10-13$ & 0 & 0.15 \\
\hline $12-13$ & 0 & 1.05 \\
\hline $13-13$ & 0 & 0.225 \\
\hline $9-14$ & 1 & 0.3 \\
\hline $10-14$ & 1 & 0.15 \\
\hline $12-14$ & 1 & 1.05 \\
\hline 13-14 & 0 & 0.45 \\
\hline $14-14$ & 0 & 0.225 \\
\hline $9-15$ & 0 & 0.2 \\
\hline $10-15$ & 0 & 0.1 \\
\hline $12-15$ & 1 & 0.7 \\
\hline $13-15$ & 1 & 0.3 \\
\hline $14-15$ & 0 & 0.3 \\
\hline $15-15$ & 0 & 0.1 \\
\hline $9-16$ & 0 & 0.2 \\
\hline $10-16$ & 0 & 0.1 \\
\hline $12-16$ & 1 & 0.7 \\
\hline 13-16 & 1 & 0.3 \\
\hline $14-16$ & 0 & 0.3 \\
\hline $15-16$ & 0 & 0.2 \\
\hline $16-16$ & 0 & 0.1 \\
\hline
\end{tabular}

\begin{tabular}{ccc}
\hline $\begin{array}{l}\text { Table 9b: Summary of Genotype } \\
\text { (D14S1434) }\end{array}$ & & \\
\hline Genotype & No. & No. \\
Observed & Expected \\
$13-13$ & 0 & 0.364 \\
$13-15$ & 0 & 0.545 \\
$15-15$ & 1 & 0.205 \\
$13-17$ & 0 & 0.182 \\
$15-17$ & 0 & 0.136 \\
$17-17$ & 0 & 0.023 \\
$13-19$ & 1 & 0.364 \\
$15-19$ & 0 & 0.273 \\
$17-19$ & 0 & 0.091 \\
$19-19$ & 0 & 0.091 \\
$13-20$ & 3 & 2.182 \\
$15-20$ & 1 & 1.636 \\
$17-20$ & 1 & 0.545 \\
$19-20$ & 1 & 1.091 \\
$20-20$ & 3 & 3.273 \\
\hline & &
\end{tabular}

The heterozygosity of the D14S1434 was lower than that observed in the Chinese Han population (0.695) (Jai et al.2012) and the Korean population $(0.770)$ and the 0.8227 observed in unidentified remains among Mexican American (Eisenberg and Planz, 2007). The European populations in Italy, Poland and the Brazilian population in Parana have been demonstrated to have heterozygozity values of $0.69,0.68$ and 0.71 respectively. Hausa population has been previously indicated to exhibit high genetic variability. In a global analysis of dinucleotide 
repeats, the Hausa were found to present the highest heterozygosity of all the populations studied (Deka et al. 1995).

A test of Hardy-Weinberg equilibrium for the observed alleles in both loci did not detect any significant deviation from expected frequencies at the $5 \%$ level of significance (Table 3 ), even when subjected to Fischer's exact test. Conformity with HWE is generally observed, unless (a) a population is isolated and/or has a small effective size or (b) the involved locus has an imperfect or complex repeat motif. Due to the level of kinship relationship and the high level of inbreeding expected in the sample, bias-adjusted $F_{I S}$ and $F_{S T}$ levels (Nei, 1987) were computed even though the samples all belong to a single population. The locus D14S1434 actually shows $6.5 \%$ more homozygotes than expected. The deviation from HWE at this loci with $F_{\text {IS }}$ of 0.0065 (Table 7) do indicate a certain amount of inbreeding, though this was not significant as seen from the $p$-value of 0.224 and an exact p-value of 0.305 . The US national Research Council report (Balding, 2013) actually recommends that a conservative estimate of 0.01 is to be expected in populations examined for forensic data and suggests that a value of 0.03 (Table 3) indicates that cousin mating exist in such population.

Relatively high values were obtained for the Power of Exclusion for a combination of both loci in the Hausa population (0.84 for D9S1122 and 0.61 for D14S1434) (Table 8) when compared with studies of the markers in other populations (Cigliero et al. 2009; Malaghini et al. 2009; Reichert and Pawłowski 2009). The combined maximum power of exclusion for both markers is 0.97 (Table 8) indicating that it can exclude a non-father from paternity and this value can be increased when these loci are tested alongside other STR systems. The miniSTRs D9S1122 and D14S1434 both demonstrate a very high ability to identify individuals and differentiate family relationships including siblings and other types of avuncular relationships.

\section{CONCLUSION}

It is an established fact, that mini-STR can be used in profiling a degraded DNA sample. The major purview of this study focused on the ability of the loci studied to efficiently differentiate between closely related individuals especially in a Nigerian population. The results of this study as discussed above show that both mini-STRs loci demomstrate high ability to identify individuals and differentiate family relationships in the Hausa population. We therefore reccommend this study be replicated in other Nigerian ethnic population even with more markers as, these markers will be an important tool for forensic identification and paternity testing in Nigeria.

\section{ACKNOWLEDGEMENTS}

The authors want to acknowledge the assistance of the Aminu Kano Teaching Hospital. Our gratitude also goes to the participants of this research.

\section{REFERENCES}

Alford, R. L., Hammond, H A., Coto, I and C. T. Caskey (1994). Rapid and Efficient

Resolution of Parentage by Amplification of Short Tandem Repeats. American Journal of Human Genetics 55(1): 190-95.

Awe, E T., Akpan, U. U., and Adekoya, K. O. (2017). Evaluation of Two MiniSTR Loci Mutation Events in 5 Father-Mother-Child Trios of Yoruba Origin. Nigerian Journal of Biotechnology, https://dx.doi.org/10.4314/.v33i1.17.

Balding, D J. (2013). Evaluation of Mixed-Source, Low-Template DNA Profiles in Forensic Science. Proc Natl Acad Sci U S A 110. doi:10.1073/pnas.1219739110.

Butler, J M. (2005). Forensic DNA Typing: Biology, Technology, and Genetics of STR Markers. New York: Elsevier Academic Press.

Butler, J. M. (2006). Genetics and Genomics of Core Short Tandem Repeat Loci Used in Human Identity Testing. Journal of Forensic Sciences 51(2): 253-65. doi:10.1111/j.1556-4029.2006.00046.x.

Butler, J. M., Shen, Y. and McCord, B. R. (2003). The Development of Reduced Size STR Amplicons as Tools for Analysis of 
Degraded DNA. Journal of Forensic

Sciences 48(5): 1054-64.

doi:10.1520/JFS2003043.

Chatumal, W., Markalanda, D. A., Illeperuma, R.

J., Ranawaka, G. R. and Fernandopulle, N.

D. (2010). Population Study of the

Combined DNA Index System (CODIS)

Core Loci D3S1358 D5S818 D8S1179

Short Tandem Repeat (STR)

Polymorphisms in Sri Lanka. Journal of the

National Science Foundation of Sri Lanka 38(1): 65-68.

Chung, U., Hwan, Y., Park, M., Cho, S., Shin, K. and Yang, W. (2006). Forensic evaluation of nine miniSTR loci to aid analysis of degraded DNA in Koreans. Forensic Science International, 46: 37-45

Coble, M. D. and Butler, J. M. (2005).

Characterization of New miniSTR Loci to Aid Analysis of Degraded DNA. Journal of Forensic Sciences, 50(1): 43-53.

Deka, R., Jin, L., Shriver, M. D., Yu, L. M. DeCroo, S., Hundrieser, J., Bunker, C. H., Ferrell, R. E. and Chakraborty, R. (1995). Population Genetics of Dinucleotide (dCdA)n.(dG-dT) Polymorphisms in World Populations. American Journal of Human Genetics. 56:461-474.

Eisenberg, A. J., and PhD. (2007). Field Test of Current Technology Used in the Identification of Unidentified Remains, 1-81.

Fabusoro, E. (2007). Key Issues in Livelihood Security of Migrant Fulani Pastoralists. Department of Agricultural Extension and Rural Development, University of Agriculture, P.M.B. 2240, Abeokuta, Ogun State, Nigeria, 1-20.

Hammond, H. A., L. Jin, Zhong, Y., Caskey, C. T. and Chakraborty, R. (1994). Evaluation of 13 Short Tandem Repeat Loci for Use in Personal Identification Applications. American Journal of Human Genetics, 55: 175-89.

Hill, C. R., Margaret C. K., Michael D. C., and Butler, J. M. (2008). Characterization of 26 miniSTR Loci for Improved Analysis of Degraded DNA Samples. Journal of Forensic Sciences 53(1): 73-80.

HILL, P. (1972). Rural Hausa: A Village and a Setting. Cambridge: University Press.
Jai, Z., Shi, M., Jiang, S., Wu, W., Li, Y., Wu, J. and Hou, Y. (2012). Further

Characterization of Six miniSTR Loci in the Han Population from China. Forensic Science International, 94: 37-41.

Jeffreys, A. J., Wilson, V. and Thein, S. L. (1992). "Hypervariable 'Minisatellite' Regions in Human DNA. 1985."

Biotechnology (Reading, Mass.), 24: 46772.

Klintschar, M, and Crevenna, R. (1996). "Validation of the STR System FXIIIB for Forensic Purposes in an Austrian Population Sample." Forensic Science International 81(1): 35-42.

Malaghini, M., Schneider, V. and Leite, F. (2009). Genetic Analysis of 9 Non-CODIS miniSTR Loci in the Brazilian Population of Parana. Forensic Science International: Genetics Supplement Series 2(1): 359-60.

Moretti, T. R., Baumstark, A. L., Defenbaugh, D. A., Keys, K. M., Smerick, J. B. and Budowle, B. (2001). Validation of Short Tandem Repeats (STRs) for Forensic Usage: Performance Testing of Fluorescent Multiplex STR Systems and Analysis of Authentic and Simulated Forensic Samples. Journal of Forensic Sciences 46(3): 64760.

Nei, M. (1987). Molecular Evolutionary Genetics. New York: Coloumbia University Press.

Otite, O. (1991). Marriage And Family Systems In Nigeria. International Journal of Sociology of the Family, 21(2). International Journals, 15-54.

Reichert, M. and Ryszard P. (2009). "Population Genetics of Six miniSTR Loci (D1S1677, D2S441, D4S2364, D10S1248, D14S1434, D22S1045) in a Polish Population." Legal Medicine 11 (3): 147-48.

Roewer, L. (2013). DNA Fingerprinting in Forensics: Past, Present, Future. Investigative Genetics 4(1): 22.

Sorçaburu, C. S., Previderè, F. C. and Fattorini, P. (2009). Allele Frequencies of Three MiniSTR Loci (D22S1045, D14S1434 and D10S1248) in North-East Italy. Forensic Science International: Genetics Supplement Series, 2(1): 378-79. 